\title{
Research results from a registry supporting efforts to improve maternal and child health in low and middle income countries
}

\author{
Robert L. Goldenberg ${ }^{1 *}$, Elizabeth M. McClure ${ }^{2}$, Carl L. Bose ${ }^{3}$, Alan H. Jobe ${ }^{4}$ and José M Belizán ${ }^{5}$
}

\begin{abstract}
The National Institute of Child Health and Human Development created and continues to support the Global Network for Women's and Children's Health Research, a partnership between research institutions in the US and low-middle income countries. This commentary describes a series of 15 papers emanating from the Global Network's Maternal and Newborn Health Registry. Using data from 2010 to 2013, the series of papers describe nearly 300,000 pregnancies in 7 sites in 6 countries - India (2 sites), Pakistan, Kenya, Zambia, Guatemala and Argentina. These papers cover a wide range of topics including several dealing with efforts made to ensure data quality, and others reporting on specific pregnancy outcomes including maternal mortality, stillbirth and neonatal mortality. Topics ranging from antenatal care, adolescent pregnancy, obstructed labor, factors associated with early initiation of breast feeding and maintenance of exclusive breast feeding and contraceptive usage are presented. In addition, case studies evaluating changes in mortality over time in 3 countries - India, Pakistan and Guatemala - are presented. In order to make progress in improving pregnancy outcomes in low-income countries, data of this quality are needed.
\end{abstract}

\section{Manuscript}

In high-income countries during the last century, there have been massive reductions in maternal, fetal and neonatal mortality. However, in many low-income and some middle income countries (LMIC), improvements in these outcomes have been slow to materialize $[1,2]$. In these areas, maternal mortality is often a hundred-fold and fetal and neonatal mortality 20 -fold greater than in high income countries. Reasons for these differences are often not clear, but certainly include a large number of non-facility births, untrained and unskilled birth attendants and lack of basic medical equipment and medications. World-wide, an estimated 60 million women give birth each year outside of health facilities, mainly at home. Fifty-two million of these births are assisted by a traditional birth attendant or family member and not a skilled birth attendant [3].

In order to improve outcomes, policy makers in LMIC countries as well as members of the global health

\footnotetext{
* Correspondence: rlg88@columbia.edu

'Department of Obstetrics and Gynecology, Columbia University, New York, NY, USA

Full list of author information is available at the end of the article
}

community need to know the prevalence of adverse outcomes as well as the factors associated with these outcomes. Unfortunately, in most of the areas with the worst outcomes, there are few data available upon which to base decisions on how to improve these outcomes. Two general approaches are used. The first is conducting randomized trials of specific interventions to determine if those interventions improve outcomes. The second is to monitor these outcomes and the factors that may be associated with changes in these outcomes over time. In virtually all high income countries, this later approach, often in the form of vital statistics registries, is used to provide this surveillance. However, in LMIC, this type of data is often not available, and there is little information upon which to base policy decisions. For this reason, in addition to accomplishing randomized trials of specific interventions, the Global Network for Women's and Children's Health Research (Global Network) initiated the registry described below.

The Maternal Newborn Health Registry (MNHR) of the Eunice Kennedy Shriver National Institute of Child Health and Human Development's Global Network was 
created in 2008. Prior to that time, a prototype of the MNHR was used to measure outcomes in the Global Network's First Breath Trial [4]. On completion of the trial, the investigators maintained and improved the prototype because they appreciated the scientific value of collecting prospective data describing populationbased demographics, processes of care and pregnancy outcomes in low-resource communities. The MNHR is now used to monitor trends in these characteristics over time. It also serves as a method to obtain outcomes for a number of cluster randomized trials including those on antenatal corticosteroids, emergency obstetric and neonatal care, and routine obstetric ultrasound.

One of the outstanding characteristics of the MNHR is its sheer volume. Monitoring nearly 70,000 pregnant women per year has allowed the MNHR to collect data on more than 500,000 births over its history, which provides a sufficient sample size to assess stillbirth and neonatal mortality, as well as maternal mortality, a relatively rare event. We believe this is one of the largest LMIC registries of prospectively collected pregnancy data in existence. Another attribute of the MNHR is the diversity and stability of the Global Network sites. The Global Network includes sites from sub-Saharan Africa (Democratic Republic of Congo [DRC], Kenya, and Zambia), South Asia (Belgaum and Nagpur, India, Pakistan) and Latin America (Guatemala, Argentina). Since its inception, only one site has been added and only one site has been dropped from the MNHR. The GN sites also show a great diversity with respect to the characteristics of the women and the resources available for their care. Some sites have almost universal hospital delivery while others show a proportion of home deliveries as high as $58 \%$. In some sites, $70 \%$ of deliveries are assisted by physicians whereas in other sites, $55 \%$ of deliveries are assisted by traditional birth attendants [5]. Within each country site, between 6 and 20 geographic areas (clusters), with about 500 deliveries per year, are closely monitored to provide data for the MNHR.

In this supplement, we have assembled manuscripts that not only highlight the productivity and value of the MNHR, but also address issues crucial to improving pregnancy outcomes in these sites. When developing the guidelines for the manuscripts, we decided to restrict the data reported to that collected from 2010 to 2013, which included data from all sites which were active during that time. The pregnancy outcomes for 2014 births were not complete when the analysis data sets were created, and although data from 2008 to 2009 were available for some sites, we generally elected not to present that data because the data forms changed substantially early in its history, and the quality of data improved in later years.

This supplement can be seen conceptually as divided into several components. The first component deals with registry management and quality control. Four papers are included in this category which includes the overall description of the MNHR by Bose, et al. [5]. Goudar et al. summarize the extensive work the registry investigators have put into ensuring that the MNHR has complete and quality data, focusing on defined metrics to evaluate the quality of the data and the ongoing monitoring methodologies employed by the registry [6]. Kodkany et al. describe how the Belgaum, India staff utilize Ministry of Health family planning and other pregnancy registers to ensure nearly complete registration of pregnancies [7]. Also, to facilitate first trimester enrollment in the MNHR, their staff conduct frequent house-to-house canvassing to identify pregnant women. This process allows tracking of all outcomes of pregnancy, including first trimester losses. Finally, Marete et al. document the very low rate of women lost to follow up across all sites and also the characteristics associated with those lost compared to those for whom follow up data were available [8]. For population-based registries, complete ascertainment is crucial and these papers document the extent to which the sites have endeavored to ensure both the completeness and accuracy of the data.

One of the important features of the MNHR is its ability to evaluate important pregnancy outcomes including maternal, fetal and neonatal mortality. Bauserman et al. report the prevalence of maternal mortality and the characteristics associated with mortality [9]. With more than 500,000 births, this is one of the only low-resource country data sets that have a sufficient number of maternal deaths to evaluate this outcome. Of note, the maternal mortality ratio decreased from 166 in 2010 to 126 in 2013 among all sites, with the exception of Pakistan where maternal mortality increased over that period. Similarly, the paper by Dhaded et al. addressed the risk factors associated with neonatal mortality and reported a 7 -day neonatal mortality rate (NMR) of 20.6 per 1000 live births and a 28-day NMR of 25.7 per 1000 live births [10]. The very wide range in 28 day NMR across the sites, ranging from 10 in Argentina to 50 in Pakistan, was emphasized. McClure et al. describe the risk factors associated with over 2,500 stillbirths [11]. Importantly, they report that the majority of stillbirths in these lowresource areas were not macerated and many were greater than $2500 \mathrm{~g}$ at birth. These results strongly suggest that many stillbirths occurred in labor and were of sufficient size and maturity to survive had they been delivered alive. Thus, with appropriate obstetrical care most of these deaths were preventable. Across all three studies, worse pregnancy outcomes were generally observed among women with lower education levels, less access to antenatal care and those who were delivered outside the formal health setting.

Four papers in this series explore specific topics that are of special interest to the public health community. 
Althabe et al. report wide ranges in the percent of adolescent pregnancies across the sites [12]. For example, the proportion of births to adolescents in the sub-Saharan African and Latin American sites ranged from $16.1 \%$ (Guatemala) to $26.0 \%$ (Argentina). In the South Asian sites this proportion ranged from $2.0 \%$ (Nagpur, India) to $9.6 \%$ (Belgaum, India). In this study, the risks for adverse maternal outcomes among adolescents were not markedly different than those of women in their twenties. However, risks of preterm birth and LBW were significantly higher among both early and older adolescents, with the highest risks observed in the youngest (<15 years) group. Harrison et al. examined risk factors related to prolonged and obstructed labor [13]. Virtually every pregnancy outcome was worse in women with prolonged/obstructed labor, and these outcomes were particularly bad among women in the African sites compared to women in other Global Network sites. Patel et al. identified characteristics associated with lack of breastfeeding in low-resource settings and associated outcomes [14]. Pasha et al. report that, despite relatively high contraceptive usage in a few of the sites, overall there was a large unmet need for family planning services across the sites [15]. If contraceptive usage was increased, teenage pregnancies reduced, better obstetric care provided for women having prolonged labors, and better support of breast feeding, we believe many of the adverse pregnancy outcomes in these sites could be reduced.

Finally there are three papers focusing on issues related to pregnancy outcomes in a single country. Goudar et al. examined the relationship between increasing use of facilities for delivery and pregnancy outcomes in sites in India, where substantial government effort has promoted facility rather than home births [16]. They report a modest decline in the stillbirth rate that was temporally associated with an increase in the prevalence of facility births, but not a corresponding improvement in neonatal mortality. Garces et al. report reductions in maternal mortality, fetal mortality and neonatal mortality in the Western Highlands of Guatemala between 2010 and 2013 [17]. Those reductions were temporally correlated with increasing hospital delivery, births attended by skilled rather than unskilled birth attendants, and increasing use of caesarean section. The reduction in infant mortality was most pronounced in infants born between $1500 \mathrm{~g}$ and $2500 \mathrm{~g}$. Pasha et al. report disappointing trends in obstetric and neonatal care and pregnancy outcomes in the Thatta area of Pakistan [18]. Maternal, fetal and neonatal mortality were two to three-fold higher in Pakistan than in any other site in the Global Network. These differences were associated with lower levels of maternal education and lower quality of antenatal and obstetric care in Pakistan compared with the other sites. Taken together, these papers demonstrate that improvements in outcomes can occur with better access to and utilization of facility care for delivery. On the other hand, the data from Pakistan illustrate the very poor pregnancy outcomes that occur when a poor, uneducated population is provided low quality care.

In summary, the breadth of topics covered by the papers in this supplement using data from a prospective pregnancy outcome registry presents a powerful picture of pregnancy and its outcomes in the developing world and shows the value of a population-based registry focused on pregnancy. With additional years, trends over time will become even more apparent, and the scientific value of the registry should become even greater. In addition to the manuscripts in this supplement, previously published papers using data from the MNHR have described the relationship between maternal mortality and stillbirth and neonatal mortality. Papers describing the methodology for determining maternal, fetal and neonatal causes of death and the effects of indoor air pollution on pregnancy outcomes in the Global Network sites are in press. Registry data has also been incorporated into larger data bases to evaluate neonatal infections and the role of birth weight on neonatal mortality. We believe that the MNHR has made a substantive contribution by providing information to inform public health and medical strategies to improve care and to reduce pregnancy-related mortality.

\section{Author details}

${ }^{1}$ Department of Obstetrics and Gynecology, Columbia University, New York, NY, USA. ${ }^{2}$ RTI International, Durham, NC, USA. ${ }^{3}$ Department of Pediatrics, Division of Neonatal-Perinatal Medicine, University of North Carolina School of Medicine, Chapel Hill, NC, USA. ${ }^{4}$ Cincinnati Children's Hospital, Cincinnati, $\mathrm{OH}$, USA. ${ }^{5}$ Editor-in-Chief of Reproductive Health, Institute for Clinical Effectiveness, Buenos Aires, Argentina.

Received: 22 May 2015 Accepted: 27 May 2015

Published online: 03 June 2015

\section{References}

1. Requejo JH, Bryce J, Barros AJ, Berman P, Bhutta Z, Chopra M, et al. Countdown to 2015 and beyond: fulfilling the health agenda for women and children. Lancet. 2015;385(9966):466-76.

2. Lawn JE, Blencowe H, Oza S, You D, Lee AC, Waiswa P, et al. Every Newborn: progress, priorities, and potential beyond survival. Lancet. 2014;384(9938):189-205.

3. Darmstadt GL, Lee AC, Cousens S, Sibley L, Bhutta ZA, Donnay F, et al. 60 Million non-facility births: who can deliver in community settings to reduce intrapartum-related deaths? Int J Gynaecol Obstet. 2009;107 Suppl 1:S89-112.

4. Carlo WA, Goudar SS, Jehan I, Chomba E, Tshefu A, Garces A, et al. Newborn-care training and perinatal mortality in developing countries. $\mathrm{N}$ Engl J Med. 2010;362(7):614-23.

5. Bose CL, Bauserman M, Goldenberg RL, Goudar SS, McClure EM, Pasha O, et al. The Global Network Maternal Newborn Health Registry: a multinational, community-based registry of pregnancy outcomes. Reproductive Health. (in press).

6. Goudar SS, Stolka KB, Koso-Thomas M, McClure EM, Carlo WA, Goldenberg RL, et al. The Global Network's Maternal Newborn Health Registry: data quality monitoring and performance metrics. Reproductive Health. (in press).

7. Kodkany B, Derman RJ, Honnungar N, Tyagi N, Goudar SS, Mastiholi S, et al. Establishment of a Maternal Newborn Health Registry in the Belgaum District of Karnataka, India. Reproductive Health. (in press). 
8. Marete I, Tenge C, Chemweno C, Bucher S, Pasha O, Goudar SS, et al. Loss to followup among pregnant women in a multi-country, community-based maternal and newborn health registry: a prospective, cohort study. Reproductive Health. (in press).

9. Bauserman M, Lokangaka A, Thorsten V, Tshefu A, Goudar SS, Esamai F, et al. Risk factors for maternal death in low- and middle-income countries: a prospective longitudinal cohort analysis. Reproductive Health. (in press).

10. Dhaded SM, Somannavar M, Vernekar S, Goudar SS, Ramadurg U, Mwenche M, et al. Neonatal mortality and risk factors 2010-2013: a prospective, populationbased Global Network cohort study. Reproductive Health. (in press).

11. McClure EM, Saleem S, Goudar SS, Moore JL, Esamai F, Garces A, et al. Still birth trends in low-middle income countries 2010-2013: a population-based, multicountry cohort study from the Global Network. Reproductive Health. (in press).

12. Althabe F, Moore J, Gibbons L, Berrueta M, Goudar SS, Chomba E, et al. Adverse maternal and perinatal outcomes in adolescent pregnancies: the Global Network's Maternal Newborn Health Registry study. Reproductive Health. (in press).

13. Harrison MS, Ali S, Pasha O, Saleem S, Althabe F, Berrueta M, et al. A prospective study of maternal, fetal, and neonatal outcomes in the setting of prolonged labor, obstructed labor and failure to progress in low- and middle-income countries. Reproductive Health. (in press).

14. Patel A, Bucher S, Pusedekar Y, Esamai F, Krebs NF, Goudar SS, et al. Factors associated with lack of early initiation of breast feeding among rural populations in low and middle income countries: a prospective, cohort study. Reproductive Health. (in press).

15. Pasha O, Goudar SS, Patel A, Garces A, Esamai F, Chomba E, et a. Postpartum contraceptive use and unmet need for family planning in 5 low-income countries. Reproductive Health. (in press).

16. Goudar SS, Goco N, Somannavar MS, Vernekar SS, Mallapur AA, Moore JL, et al. Institutional deliveries and perinatal and neonatal mortality in Southern and Central India. Reproductive Health. (in press).

17. Garces A, Mcclure EM, Hambidge KM, Krebs NF, Figueroa L, Aguilar ML, et al. Trends in perinatal deaths from 2010 to 2013 in the Guatemalan Western Highlands. Reproductive Health. (in press).

18. Pasha O, Saleem S, Ali S, Goudar SS, Garces A, Esamai F, et al. Diverging maternal, fetal and neonatal outcomes: Pakistan and other low and middle income countries in the Global Network's Maternal Newborn Health Registry. Reproductive Health. (in press).

\section{Submit your next manuscript to BioMed Central and take full advantage of:}

- Convenient online submission

- Thorough peer review

- No space constraints or color figure charges

- Immediate publication on acceptance

- Inclusion in PubMed, CAS, Scopus and Google Scholar

- Research which is freely available for redistribution 